\title{
Polar Effects on Ion Transport and Cell Proliferation Induced by GC-C Ligands in Intestinal Epithelial Cells
}

\author{
VITTORIA BUCCIGROSSI, CARLA ARMELLINO, ELIANA RUBERTO, MARIA VITTORIA BARONE, GIULIO DE MARCO, \\ CIRO ESPOSITO, AND ALFREDO GUARINO
}

\author{
Departments of Paediatrics [V.B., C.A., E.R., M.V.B., G.D.M., A.G.] and Pediatric Surgery [C.E.], University of Naples, "Federico II," \\ Naples 80131, Italy
}

\begin{abstract}
Guanylin receptor guanylate cyclase (GC-C) peaks in neonatal intestine and is involved in either enterocyte proliferation or chloride secretion. The latter is more potent when GC-C activator guanylin, or its analog Escherichia coli heat-stable enterotoxin (ST), is added to the mucosal rather than serosal side of intestinal monolayers. By using Ussing chambers, we investigated transepithelial ion transport and enterocyte proliferation and their mechanisms in response to the addition of guanylin or ST to the mucosal or serosal side of Caco-2 monolayers and in ileal specimens from neonates. GC-C activation showed a polar pattern of the effects. GC-C mucosal activation resulted in a potent cGMP-chloride secretion activation and in a marginal enterocyte proliferation. Conversely, serosal GC-C activation induced a potent enterocyte proliferation, through MAP kinase ERK 1/2. Finally, the inhibition of ERK1/2 enhanced the Isc increase in response to serosal but not to mucosal ST stimulation, indicating that ERK1/2 also acts as a brake of chloride secretion. These data suggest that the guanylin/GC-C system plays a key role in early postnatal intestinal adaptation exploiting the polar structure of enterocyte. (Pediatr Res 69: 17-22, 2011)
\end{abstract}

$\mathrm{T}$ he human intestinal epithelium is organized in crypt-villus units with stem cells in the crypt that proliferate and mature while migrating along the villus (1). The mature enterocyte is a polarized cell whose structure is functional to create a barrier between the intestinal environment and the bloodstream and to transport ions, solutes, and macromolecules between the apical and basal compartments (2). A number of autocrine and paracrine messengers act on either side of the enterocyte to modulate these functions (3). Human guanylin is one such modulator, and similar to its bacterial analog, Escherichia coli heat-stable enterotoxin (ST), it binds to intestinal guanylyl cyclase $\mathrm{C}$ (GC-C) and induces an increase in cGMP (4) that triggers active chloride secretion. GC-C receptors are located along the entire intestine of mammals including humans (5-7). However, GC-C is in a polar fashion distributed in the enterocyte, with a lower receptor density in the basolateral than in brush border membranes (8). We previously reported that the rate of chloride secretion is lower when guanylin is added to the basolateral side than to the apical side of intestinal epithelium mounted in Ussing chambers (9).

Received February 24, 2010; accepted September 9, 2010

Correspondence: Alfredo Guarino, M.D., Ph.D., Department of Pediatrics, University "Federico II," Via S. Pansini 5, 80131 Naples, Italy; e-mail: alfguari@unina.it

Supported by a grant from the Italian Ministry of University and Scientific Research; Progetti di Ricerca di Interesse Nazionale_-PRIN 2007.
In addition, guanylin receptor density is age dependent (7), and the number of GC-C receptors is highest in the small intestine and colon of newborn infants and decreases with age (10). Because GC-C peaks sharply at birth, we suggested that the abundance of GC-C receptors in neonates induces copious intestinal water secretion on guanylin stimulation that allows meconium expulsion in the very first days of life (9). Guanylin is the endogenous ligand of GC-C. It is produced in intestinal cells, is detected in both the intestinal lumen and the blood (11), and induces chloride secretion. E. coli ST is the exogenous analog of guanylin. It exerts the same effects on ion secretion as guanylin but is more potent (9).

GC-C has been implicated in the regulation of enterocyte proliferation and differentiation along the crypt-villus axis. Deletion of cGMP signaling in GC-C-null mice selectively induced crypt hyperplasia with a decreasing intestinal cephalocaudal gradient (12). Crypt hyperplasia reflected, in part, an increase in proliferating cells and an acceleration of cell cycle. These changes were associated with an increase in migration and apoptosis along the crypt-villus axis. These effects were more evident in small intestine than in colon (12). The same effects were observed in the colon of guanylin-null mice but not in their ileum (13). Indeed, cGMP levels, cell migration, and apoptosis were similar in the colon of guanylin-null mice and of wild-type mice, which suggests activation of compensatory mechanisms (13). Recently, Garin-Laflam et al. (14) reported that GC-C activation reduces apoptosis in intestinal epithelial cells. They observed an increased apoptotic sensitivity of intestinal epithelial cells in uroguanylin knockout mice and in GC-C knockout mice after radiation and provided evidence that cGMP is a primary downstream mediator of GC-C activation in protecting the enterocyte from radiationinduced apoptosis.

The different receptor distribution in basolateral and apical compartments of enterocytes suggests a specific function. We hypothesized that the role of $\mathrm{GC}-\mathrm{C}$ in the regulation of intestinal ion transport and cell proliferation depends on cell polarity and that the two effects are polarized in the enterocyte. To test this hypothesis, we added guanylin to the muco-

Abbreviations: GC-C, intestinal guanylate cyclase; BrdU, bromodeoxyuridine; ERK, extracellular signal-regulated kinase; ST, E. coli heat stable enterotoxin toxin; Caco-2 cells, human colonic adenocarcinoma cells; M, mucosal side; $\mathbf{S}$, serosal side 
sal or serosal side of polarized enterocyte monolayers and monitored cell cycle progression. Cell cycle progression involves the activation of the intracellular MAP kinase cascade (15) that leads to DNA synthesis in the nuclei. Therefore, we investigated whether the extracellular signal-regulated kinase (ERK) pathway, a member of MAP kinase family, was involved in the guanylin-induced cell response. Finally, we investigated the effects of GC-C activation in ex-vivo experiments on intestinal specimens obtained from human neonates.

\section{MATERIALS AND METHODS}

Cell growth and culture. Caco-2 cells were used as small intestinal cell model. Caco-2 cell monolayers are widely used as model of enterocyte proliferation and ion transport studies $(16,17)$. After $15 \mathrm{~d}$ postconfluence, the cells exhibit a well-differentiated brush border on the apical surface and tight junctions with typical small-intestinal microvillus hydrolases and nutrient transporters. Caco-2 cells were grown in DMEM essential medium with high glucose concentration $(4.5 \mathrm{~g} / \mathrm{L})$ at $37^{\circ} \mathrm{C}$ in $5 \% \mathrm{CO}_{2}$ atmosphere. The medium was supplemented with $10 \%$ fetal bovine serum, $1 \%$ nonessential amino acids, penicillin $(50 \mathrm{mU} / \mathrm{mL})$, and streptomycin $(50 \mu \mathrm{g} / \mathrm{mL})$ and changed daily. To obtain a cell monolayer typical of small intestinal mucosa, Caco-2 were grown on uncoated, polycarbonate Transwell filters (Costar Italia, Milan, Italy) for up $15 \mathrm{~d}$ postconfluence. Cells were used between the 22nd and 37 th passage.

Cell proliferation. We used ST in the experimental model because it is more potent than guanylin. However, all experiments were repeated with guanylin. Caco-2 cells were serum starved for $24 \mathrm{~h}$ and then stimulated with guanylin or ST. One hour before paraformaldehyde fixing and Triton X-100 permeabilizing, bromodeoxyuridine (BrdU; Roche Diagnostics, Monza, Italy) was added to the medium at the final concentration of $100 \mu \mathrm{M}$. Incorporation of BrdU was monitored by treating cells with an anti-BrdU antibody (Invitrogen Corporation, CA) and a mouse secondary tetramethylrhodamine isothiocyanate-conjugated antibody (Jackson, ImmunoResearch, PA). The $\mathrm{G}_{0} \rightarrow \mathrm{S}$ transition was expressed as the ratio between the number of cells incorporating BrdU and the total number of cells. Stained cells were analyzed with an Axionplan 2 fluorescent microscope (Carl Zeiss MicroImaging, Inc., Jena, Germany).

MAPK ERK1/2. Cells were serum starved for $48 \mathrm{~h}$ before stimulation. Guanylin or ST was added at the concentration of $10^{-6} \mathrm{~mol} / \mathrm{L}$ for $15 \mathrm{~min}$ or for the indicated time in the time-course experiments. The cells were then lysed in lysis buffer ( $40 \mathrm{mM}$ Tris pH7.5, $150 \mathrm{mM} \mathrm{NaCl}, 1 \mathrm{mM}$ EDTA, $1 \%$ Triton X-100, $40 \mathrm{mM}$ glycerophosphate, $0.1 \mathrm{mM}$ phenylmethylsulfonylfluoride, $10 \mu \mathrm{g} / \mathrm{mL}$ leupeptin, $1 \mu \mathrm{g} / \mathrm{mL}$ pepstatin, $10 \mu \mathrm{g} / \mathrm{mL}$ aprotinin, $0.1 \mathrm{mM}$ $\mathrm{NaF}, 0.1 \mathrm{mM}$ sodium pyrophosphate, and $0.1 \mathrm{mM}$ orthovanadate). Total protein supernatants were measured with the BIORAD protein assay (BioRad Laboratories, Segrate, Italy). Equal amounts of proteins were run on a $12 \%$ Bis-Tris Gel NuPAGE (Invitrogen) and transferred onto a nitrocellulose filter. The filter was incubated with a mouse MAb specific for the phosphorylated (activated) form of ERK1/2 (Santa Cruz Biotechnology, CA). Speciesspecific HRP-conjugated secondary antibodies (GE Healthcare, Milan, Italy) and enhanced chemiluminescence (ECL Plus; GE Healthcare, Milan, Italy) were used for protein visualization. Filters were then stripped and reprobed with a rabbit MAb specific for ERK1/2 (total) to verify that all samples contained comparable levels of the ERK1/2 protein. Signals from doublet bands were acquired with a Mustek 1248UB scanner, and the Scion Image program was used for densitometric analyses.

Transepithelial ion transport. Each filter with a Caco-2 cell monolayer was mounted as a flat sheet between the mucosal and serosal compartments of Ussing chambers as previously described (9). Short circuit current (Isc) was measured before and after guanylin or ST $\left(10^{-6} \mathrm{~mol} / \mathrm{L}\right)$ were added to the serosal or mucosal side of cell monolayers. Isc is expressed as microambert per square centimeter. Cell viability was assessed at the end of each experiment by measuring the electrical response to serosal addition of $5 \mathrm{mmol}$ of theophylline. An Isc increase of at least 3 -fold compared with the preaddition value was considered proof of cell viability. To investigate the role of ERK1/2, the specific inhibitor PD098059 $(40 \mu \mathrm{M})$ was added 30 min before ST.

cGMP intracellular concentrations. cGMP was measured with a RIA commercial kit (cGMP ${ }^{125}$ I assay system; GE Healthcare, Milan), according to the manufacturer's instructions. Results were calculated as picomoles of cGMP per square centimeter and expressed as fold increase over basal level.

Experiments with human small intestinal specimens. Human small intestinal specimens were obtained from three newborns undergoing surgery because of intestinal obstruction. Ileal mucosa sampled at the edge of the resection was used for organ culture. Intestinal tissue was flushed with cold PBS and cut in small squares within $30 \mathrm{~min}$ of the surgical excision. Specimens were observed at the stereomicroscope to exclude necrosis and placed in tissue culture wells in DMEM with a high glucose concentration $(4.5 \mathrm{~g} / \mathrm{L}), 0.5 \%$ fetal bovine serum, $1 \%$ nonessential amino acids, $2 \%$ penicillin $(50 \mathrm{mU} / \mathrm{mL})$, and streptomycin $(50 \mathrm{mg} / \mathrm{mL})$ and incubated in $5 \%$ $\mathrm{CO}_{2} / 95 \%$ air for $1 \mathrm{~h}$ before treatment. The tissue was oriented with the mucosal side upward and treated with ST $\left(10^{-6} \mathrm{~mol} / \mathrm{L}\right)$ for $2 \mathrm{~h}$. ERK1/2 and cGMP were measured as described above. The children's parents gave their informed consent to the study. The study protocol was approved by the Ethics Committee of the School of Medicine, University of Naples Federico II (Naples, Italy).

Chemicals. All chemicals including guanylin and ST were obtained from Sigma Chemical Co.-Aldrich srl (Milan, Italy); all chemicals for cell and organ culture were from Life Technologies GIBCO BRL (Mascia Brunelli, Milan, Italy).

Statistical analysis. The $p$ values were calculated using a one-way ANOVA, and $p<0.05$ was considered statistically significant.

\section{RESULTS}

Enterocyte proliferation in response to $G C$-C activation. In fully differentiated Caco- 2 cell monolayers, all cells are synchronized in $\mathrm{G}_{0}$-phase. Incubation of Caco- 2 cell monolayers with increasing concentrations of ST resulted in an increase of BrdU incorporation, which indicates the $\mathrm{G}_{0} \rightarrow \mathrm{S}$ transition (Fig. 1A). The effect was dose dependent and more potent with serosal than mucosal GC-C activation. Simultaneous addition of ST to both sides resulted in a slightly more potent effect than that observed when ST was added to either side of the epithelial monolayer. GC-C stimulation also caused ERK1/2 activation with a polar pattern similar to that observed with ion transport, and activation was more potent with serosal addition than with mucosal addition (Fig. 1B). Guanylin induced both the $\mathrm{G}_{0} \rightarrow \mathrm{S}$ transition in polarized Caco-2 cell monolayers and ERK1/2 activation. Both effects were more pronounced when guanylin was added to the serosal side than to the mucosal side of intestinal epithelial cells (Fig. $1 C$ and $D$ ). As expected, the magnitude of both effects was lower than that induced by ST.

After serosal ST addition, ERK1/2 phosphorylation increased at $15 \mathrm{~min}$, peaked at $30 \mathrm{~min}$, and returned to basal level within $24 \mathrm{~h}$ (Fig. 2A). After mucosal ST addition, ERK1/2 phosphorylation was delayed and ended sooner than after serosal ST addition (Fig. 2A). In addition, ERK1/2 phosphorylation was less pronounced with mucosal stimulation than with serosal stimulation, further suggesting a link between ERK1/2 activation and the guanylin proliferative effect. To directly investigate whether ERK1/2 was involved in enterocyte proliferation, Caco-2 cells were preincubated with the ERK1/2-specific inhibitor, PD098059, for $24 \mathrm{~h}$ before GC-C activation (Fig. 2B). PD098059 significantly reduced the proliferative effect exerted by ST and guanylin. However, PD09059 did not completely inhibit the effect suggesting that pathways other than ERK1/2 are also involved in GC-Cinduced proliferation.

Role of ERK1/2 in GC-C-induced ion secretion. ERK1/2 is also implicated in the regulation of intestinal ion transport (18), and some evidence links ERK1/2 with GC-C signaling in ion secretion (19). Caco-2 cells were preincubated in Ussing chambers with the ERK1/2 specific inhibitor, PD098059, for $30 \mathrm{~min}$ before GC-C activation. There were no differences in 

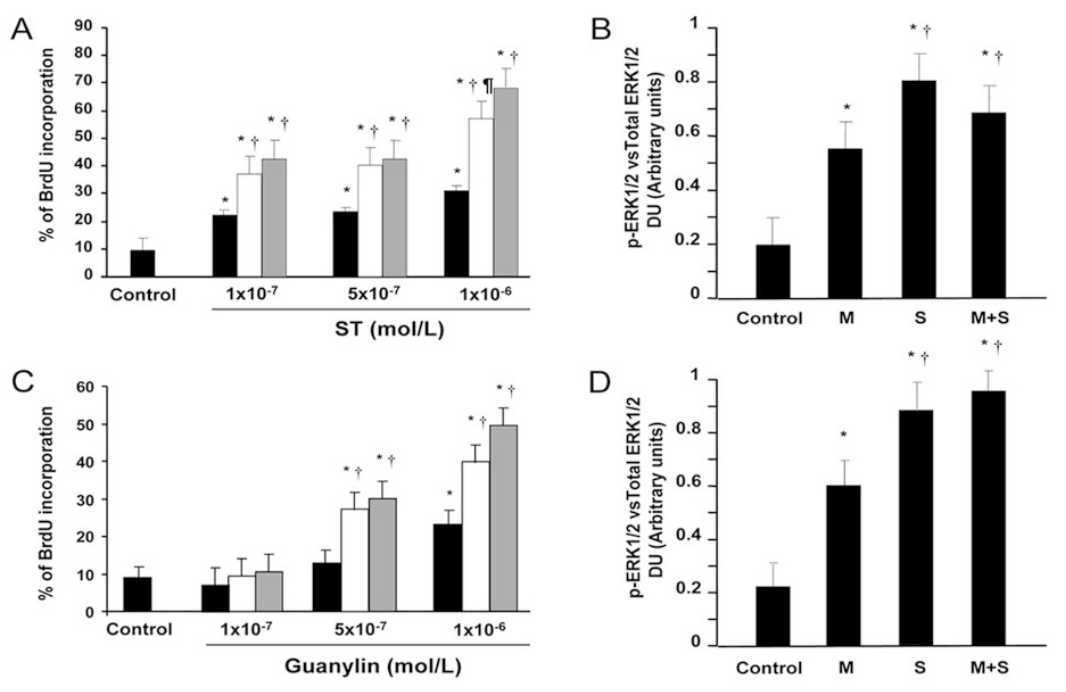

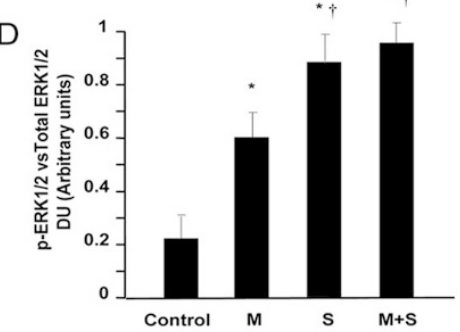

Figure 1. GC-C activation induces cell cycle progression and ERK1/2 activation in intestinal epithelial cells. Increasing ST $(A)$ or guanylin (C) concentrations were added to the mucosal (ם) or serosal ( $\square$ ) side, alone or together $\square$, of Caco-2 cell monolayers. $\mathrm{S}$ phase nuclei were evaluated by BrdU incorporation. Results are expressed as percentage of BrdU incorporation of five independent experiments and are the means \pm SEM. ST $(B)$ or guanylin $(D)(1 \times$ $10^{-6} \mathrm{~mol} / \mathrm{L}$ ) were added to the mucosal $(\mathrm{M})$ or serosal $(\mathrm{S})$ side, alone or together $(\mathrm{M}+\mathrm{S})$, of Caco-2 cell monolayers, and ERK1/2 activation was evaluated by Western blot. Results are expressed as arbitrary unit (DU) of four independent experiments and are the means \pm SEM $* p<0.05$ vs control; $\dagger p<0.05$ vs mucosal stimulation at the same concentration; $\llbracket p<0.05$ $v s$ serosal stimulation at $1 \times 10^{-7} \mathrm{~mol} / \mathrm{L}$.
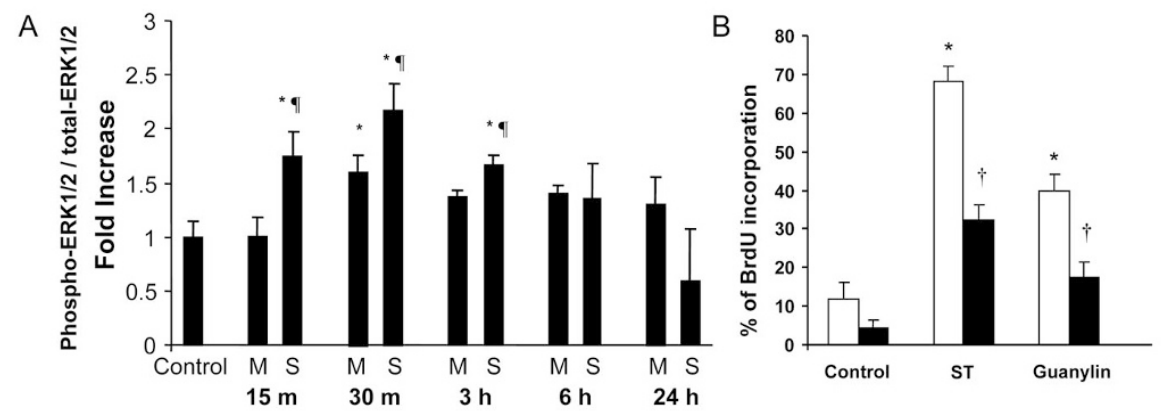

Figure 2. Role of ERK1/2 in the proliferative effect induced by GC-C activation in intestinal epithelial cell monolayers. ST $\left(1 \times 10^{-6} \mathrm{~mol} / \mathrm{L}\right)$ was added to the mucosal (M) or serosal (S) side of Caco-2 cell monolayers, and ERK1/2 activation was evaluated at different times of stimulation by Western blot. (A) Phosphorylated $v s$ total ERK1/2 ratio is expressed as fold increase $v s$ control. Mucosal GC-C activation resulted in a significant increase in ERK1/2 activation only at $30 \mathrm{~min}$. Results are expressed as fold increase $v s$ control of four independent experiments and are the means \pm SEM $* p<0.05 v s$ control, $\llbracket p<0.05$ $v s$ mucosal stimulation at the same time. (B) Caco-2 cells were stimulated with ST with ( $\square$ ) or without preincubation with PD09059 ( $\square$ ) as described in Methods section. Results are expressed as percentage of BrdU incorporation of three independent experiments and are the means \pm SEM $* p<0.05 v s$ control under standard conditions; $\dagger p<0.01$ vs standard conditions.

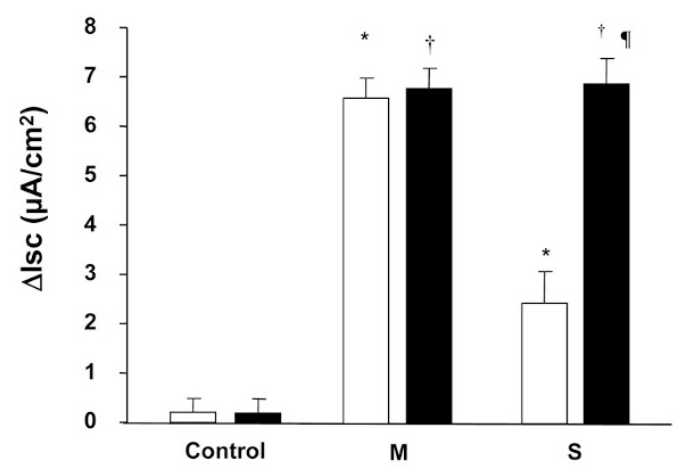

Figure 3. ERK1/2 inhibition enhances chloride secretion induced by GC-C activation at serosal but not mucosal side of intestinal epithelial cell monolayers. GC-C activation was obtained with the maximal effective dose of ST $\left(1 \times 10^{-6} \mathrm{~mol} / \mathrm{L}\right)$ at the mucosal $(\mathrm{M})$ or serosal $(\mathrm{S})$ side of Caco-2 cell monolayers. Caco-2 cells were stimulated with ST with $(\square)$ or without preincubation with PD09059 ( $\square$ ) as described in Method section. Results are expressed as $\Delta$ Isc and are the means \pm SEM of four independent experiments. $* p<0.05$ vs control under standard conditions; $\uparrow p<$ $0.01 v s$ control in the presence of PD098059; I $p<0.01$ vs ST serosal addition under standard conditions. chloride secretion with or without PD098059 when ST was added to the mucosal side. Conversely, chloride secretion was greatly enhanced in the presence of PD098059 when ST was added to the serosal side (Fig. 3). In this condition, cGMP intracellular levels did not differ from that of controls treated with ST alone (data not shown). This finding indicates that inhibition of ERK1/2 increases chloride secretion through a cGMP-independent mechanism when GC-C is activated by the serosal side but not when GC-C is activated by the mucosal side.

Effects of GC-C activation in cultured human small intestine mucosa. We next investigated the effects of GC-C activation in an ex vivo experimental model. We used ileal specimens from three newborns for intestinal organ culture. At this age, intestinal mucosa expresses the highest number of GC-C receptors $(7,10)$. Neonates A and B were $1 \mathrm{~d}$ of age and born at term. Neonate $\mathrm{C}$ was aged $8 \mathrm{~d}$ and born at the 25th week. We evaluated in parallel specimens the activation of ERK1/2 and the intracellular levels of cGMP, which is the mediator of GC-C-induced chloride secretion. GC-C serosal activation induced more potent ERK1/2 activation than mu- 

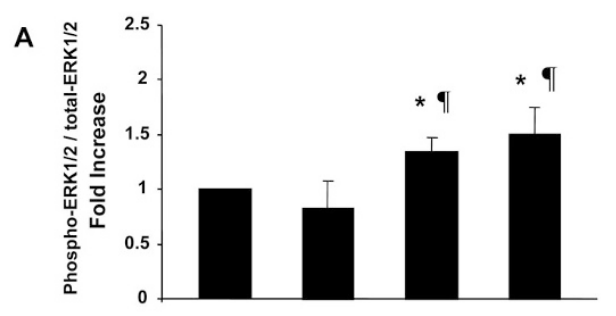

B

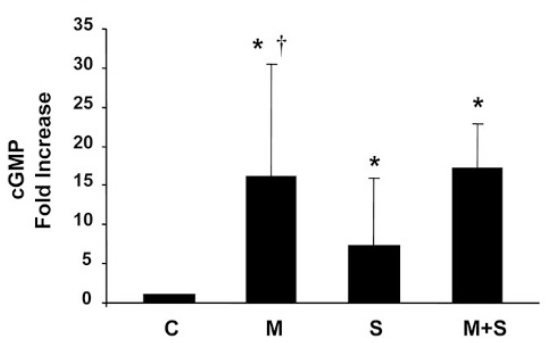

Figure 4. GC-C activation by ST induces ERK1/2 activation and cGMP levels in human intestinal mucosa. ST $\left(1 \times 10^{-6} \mathrm{~mol} / \mathrm{L}\right)$ was added to the mucosal $(\mathrm{M})$ or serosal $(\mathrm{S})$ side, alone or together $(\mathrm{M}+\mathrm{S})$, of ileum mucosa of three neonates. (A) Phosphorylated vs total ERK1/2 ratio, expressed as fold increase $v s$ control (C), significantly increased after ST addition and the effect was more potent when ST was added to the serosal side of intestinal mucosa. $(B)$ The same samples shown in $(A)$ responded to GC-C activation by increasing cGMP intracellular levels; the effect was more potent effect when GC-C was added to the mucosal side. Results are expressed as fold increase $v s$ control of three independent experiments and are the means \pm SEM $* p<0.05 v s$ control; I $p<0.01 v s$ ST mucosal addition; $\dagger p<0.01$ vs ST serosal addition.

cosal GC-C activation. cGMP intracellular levels were significantly higher after mucosal than after serosal GC-C activation in the specimens from all newborns (Fig. 4). Overall, the pattern observed in neonatal human specimens was in all similar to that observed in Caco-2 cells.

\section{DISCUSSION}

Herein, we report that guanylin induces two distinct effects in the enterocyte, on ion transport and cell proliferation, respectively, and the two effects involve two distinct pathways, namely cGMP and ERK1/2. In addition, the two effects have an inverse polar pattern: mucosal GC-C activation mainly affects ion secretion, whereas serosal GC-C activation mainly affects cell proliferation. A link between the two effects is provided by ERK1/2, which not only mediates the effect on cell proliferation but also acts as a brake of chloride secretion. Also, the latter effect has a polar pattern, being elicited by serosal but not by mucosal GC-C activation.

We previously reported that the increase in intestinal chloride secretion induced by guanylin or ST is greater with mucosal than serosal GC-C activation (9). The novel finding in this article is the polar response to GC-C activation in terms of enterocyte proliferation and the role of ERK1/2 in both Caco- 2 cells and human intestine. Guanylin induced enterocyte proliferation as shown by BrdU incorporation that indicated that cycle-arrested cells entered S-phase. This finding implicates GC-C activation in intestinal cell proliferation.

ERK1/2 is an established physiological modulator of enterocyte proliferation (20). Its activated form is highly ex- pressed in proliferating enterocytes and is reduced during differentiation (15). In addition, ERK1/2 signaling mediates the intestinal cell proliferation induced by such growth factors as glutamine (21), glucagon-like peptide-2 (22), growth hormone (23), and lactoferrin $(24,25)$.

In this study, we found that ERK1/2 mediates cell proliferation induced by guanylin. Enterocytes are polarized cells with structurally and functionally distinct basolateral and apical brush border compartments. An example of polarization is provided by the differential response of cGMP to L-arginine stimulation in intestinal mucosa (26). External signals may modulate enterocyte functions depending on the side of action (27). Guanylin receptors GC-C are mainly located on brush border membranes whereas ERK1/2 is mainly localized in the basolateral compartment of human enterocytes (28), which is consistent with the polar nature of the proliferative effect observed in intestinal epithelium.

There are evidences $(12,13)$ that the lack of GC-C receptors or ligands is associated with an increase in crypt depth and Ki-67 positive cells suggesting that the lack of GC-C signaling induces proliferation. With a different approach, we found a different result. We amplified GC-C signaling by ligands that induce cell proliferation in small intestinal enterocytes. The physiological rate of cell proliferation and apoptosis depends on a fine regulation of GC-C, which in turn is modulated by guanylin. In this article, we evaluated the biological effects of the polar GC-C stimulation.

Previously, we have reported that the magnitude of chloride secretion is greater on mucosal than serosal GC-C activation (9). Therefore, the effect of guanylin on ion transport has a polar pattern opposite to the effect on cell proliferation.

The polarization of ERK1/2 phosphorylation was not only reflected by a different magnitude but also by the time course of response. In fact, serosal stimulation induced a rapid ERK1/2 activation, which returned to basal levels within $24 \mathrm{~h}$. Mucosal stimulation also induced time-dependent ERK1/2 activation. However, this activation occurred later and was more transient than that observed on serosal stimulation, which well reflects the less potent cell cycle progression observed with mucosal than with serosal GC-C activation. The activation and subsequent deactivation of ERK1/2 is crucial for intestinal ERK1/2 signaling because its persistent activation leads to the irreversible arrest of cellular proliferation and consequent premature senescence (29).

Intestinal cell proliferation and ion secretion were triggered by the same agonist but were distinct in terms of pathways involving ERK1/2 and the GC-cGMP axis, respectively. However, there was a link between the two effects. The increase of serosal GC-C-induced chloride secretion as a consequence of ERK1/2 inhibition suggests that ERK1/2 acts as braking force on ion secretion. This effect is in agreement with the predominant basolateral ERK1/2 brush border localization in human enterocytes (28). Western blot experiments showed a modest increase in ERK1/2 on GC-C mucosal stimulation, which was probably too low to reduce ion secretion in response to serosal ST stimulation. However, ERK1/2 inhibition did not affect cGMP level, which suggests that cGMP is not the target of the homeostatic mechanisms involved in serosal ST-induced chlo- 
ride secretion. The Caco-2 cell line that we used to investigate the polarization of GC-C activation is considered a reliable model of human intestinal epithelium (30).

Because Caco-2 cells show GC-C expression (31), cGMP production under GC-C stimulation (8), and activation of specific downstream pathways (4), we consider these cells as an appropriate model for our study. GC-C is expressed along the entire intestine (32), and its abundance is age related (7). A greater number of guanylin receptors was found in intestine of newborn infants, and the number of receptors rapidly decreased with increasing age (7). In particular, GC-C activity was maximal in the first days of age (10). For this reason, we repeated the in vitro experiments in an ex vivo model, using intestinal mucosa of newborns, in which GC-C is at its highest level of expression. The differential polar response of ion transport and cell proliferation to GC-C activation was confirmed in all three specimens. This finding provides an agespecific explanation for our data. Both intestinal ion secretion and enterocyte turnover are enhanced in the first days of life. Intestinal ion secretion is needed to expel meconium, after which it must rapidly decrease, and timely modifications of transepithelial ion fluxes toward the proabsorptive state are needed to ensure hydroelectrolyte homeostasis. In parallel, the newborn intestine must proliferate rapidly to close the epithelial barrier so as to prevent bacteria and antigen translocation, which is a specific risk of the immature intestine (33). Therefore, it is conceivable that the neonatal peak of GC-C that occurs at $3 \mathrm{~d}$ of age (10) serves to ensure the rapid modifications necessary in the early intestinal adaptation. Guanylin is found both in the intestinal lumen and in the bloodstream, but its concentrations are unknown; studies in this sense are required to address this hypothesis.

Beyond the age-specific interpretation, the role of GC-C in ion transport and cell proliferation is less clear. Li et al. (34) demonstrated that the dysregulation of GC-C signaling is a key step for tumor initiation and promotion in ApcMin/ $+\mathrm{GCC}-1-$ mice.

However, deletion of endogenous ligand obtained in guanylin null mice or of GC-C receptor induced an increase of cell proliferation, migration, and apoptosis in the crypt-villus axis without spontaneous tumorigenesis $(12,13)$.Therefore, cGMP exerts a role in intestinal cell turnover, but it does not trigger intestinal cancer in the absence of a specific baseline condition such as ApcMin/+GCC-/- mice.

Finally, the role of GC-C in chloride secretion can be exploited in the treatment of constipation as suggested by a recent study on linaclotide, a GC-C agonist (35). Our finding of a polar response to GC-C provides a novel view of the role of GC-C. The differential response to polar GC-C activation leading to ion secretion and cell proliferation, with their specific mechanisms, suggests the GC-C physiological role in very early postnatal adaptation. Beyond the perinatal period, the GC-C signaling could be implicated in intestinal epithelial cell dynamics, including colon cancer cell proliferation.

Acknowledgment. We thank Fabio Albano for very helpful comments on earlier versions of this article.

\section{REFERENCES}

1. Pinto D, Clevers H 2005 Wnt control of stem cells and differentiation in the intestinal epithelium. Exp Cell Res 306:357-363

2. Höfer D, Jöns T, Kraemer J, Drenckhahn D 1998 From cytoskeleton to polarity and chemoreception in the gut epithelium. Ann N Y Acad Sci 859:75-84

3. Forte LR 1999 Guanylin regulatory peptides: structures, biological activities mediated by cyclic GMP and pathobiology. Regul Pept 81:25-39

4. Giannella RA, Mann EA 2003 E. coli heat-stable enterotoxin and guanylyl cyclase $\mathrm{C}$ : new functions and unsuspected actions. Trans Am Clin Climatol Assoc 114:67-85

5. Kuhn M 2009 Function and dysfunction of mammalian membrane guanylyl cyclase receptors: lessons from genetic mouse models and implications for human diseases. Handb Exp Pharmacol 191:47-69

6. Krause WJ, Cullingford GL, Freeman RH, Eber SL, Richardson KC, Fok KF, Currie MG, Forte LR 1994 Distribution of heat-stable enterotoxin/guanylin receptors in the intestinal tract of man and other mammals. J Anat 184:407-417

7. Cohen MB, Guarino A, Giannella RA 1988 Age-related differences in receptors for Escherichia coli heat-stable enterotoxin in the small and large intestine of children. Gastroenterology 94:367-373

8. Albano F, Brasitus T, Mann EA, Guarino A, Giannella RA 2001 Colonocyte basolateral membranes contain Escherichia coli heat-stable enterotoxin receptors. Biochem Biophys Res Commun 284:331-334

9. Albano F, De Marco G, Berni Canani R, Cirillo P, Buccigrossi V, Giannella RA, Guarino A 2005 Guanylin and E. coli heat-stable enterotoxin induce chloride secretion through direct interaction with basolateral compartment of rat and human colonic cells. Pediatr Res 58:159-163

10. Guarino A, Cohen MB, Giannella RA 1987 Small and large intestinal guanylate cyclase activity in children: effect of age and stimulation by Escherichia coli heat-stable enterotoxin. Pediatr Res 21:551-555

11. Bełtowski J 2001 Guanylin and related peptides. J Physiol Pharmacol 52:351-375

12. Li P, Lin JE, Chervoneva I, Schulz S, Waldman SA, Pitari GM 2007 Homeostatic control of the crypt-villus axis by the bacterial enterotoxin receptor guanylyl cyclase $\mathrm{C}$ restricts the proliferating compartment in intestine. Am J Pathol 171:1847-1858

13. Steinbrecher KA, Wowk SA, Rudolph JA, Witte DP, Cohen MB 2002 Targeted inactivation of the mouse guanylin gene results in altered dynamics of colonic epithelial proliferation. Am J Pathol 161:2169-2178

14. Garin-Laflam MP, Steinbrecher KA, Rudolph JA, Mao J, Cohen MB 2009 Activation of guanylate cyclase $\mathrm{C}$ signaling pathway protects intestinal epithelial cells from acute radiation-induced apoptosis. Am J Physiol Gastrointest Liver Physiol 296:G740-G749

15. Aliaga JC, Deschenes C, Beaulieu JF, Calvo EL, Rivard N 1999 Requirement of the MAP kinase cascade for cell cycle progression and differentiation of human intestinal cells. Am J Physiol 277:G631-G641

16. Watson AJ, Levine S, Donowitz M, Montrose MH 1991 Kinetics and regulation of a polarized $\mathrm{Na}(+)-\mathrm{H}+$ exchanger from Caco-2 cells, a human intestinal cell line. Am J Physiol 261:G229-G238

17. Visco V, Belleudi F, Marchese C, Leone L, Aimati L, Cardinali G, Kovacs D, Frati L, Torrisi MR 2004 Differential response to keratinocyte growth factor receptor and epidermal growth factor receptor ligands of proliferating and differentiating intestinal epithelial cells. J Cell Physiol 200:31-44

18. Chow JY, Carlstrom K, Barrett KE 2003 Growth hormone reduces chloride secretion in human colonic epithelial cells via EGF receptor and extracellular regulated kinase. Gastroenterology 125:1114-1124

19. Rao SP, Sellers Z, Crombie DL, Hogan DL, Mann EA, Childs D, Keely S, Sheil-Puopolo M, Giannella RA, Barrett KE, Isenberg JI, Pratha VS 2004 A role for guanylate cyclase $\mathrm{C}$ in acid-stimulated duodenal mucosal bicarbonate secretion. Am J Physiol Gastrointest Liver Physiol 286:G95-G101

20. Rudolph JA, Poccia JL, Cohen MB 2004 Cyclic AMP activation of the extracellular signal-regulated kinases 1 and 2: implications for intestinal cell survival through the transient inhibition of apoptosis. J Biol Chem 279:14828-14834

21. Rhoads M 1999 Glutamine signaling in intestinal cells. JPEN J Parenter Enteral Nut 23:S38-S40

22. Rowland KJ, Brubaker PL 2008 Life in the crypt: a role for glucagon-like peptide-2. Mol Cell Endocrinol 288:63-70

23. Guillermet-Guibert J, Lahlou H, Cordelier P, Bousquet C, Pyronnet S, Susini C 2005 Physiology of somatostatin receptors. J Endocrinol Invest 28:5-9

24. Buccigrossi V, De Marco G, Bruzzese E, Ombrato L, Bracale I, Polito G, Guarino A 2007 Lactoferrin induces concentration-dependent functional modulation of intestinal proliferation and differentiation. Pediatr Res 61:410-414

25. Lin TY, Chiou SH, Chen M, Kuo CD 2005 Human lactoferrin exerts bi-directional actions on PC12 cell survival via ERK1/2 pathway. Biochem Biophys Res Commun 337:330-336

26. Jin XH, Siragy HM, Guerrant RL, Carey RM 1999 Compartmentalization of extracellular cGMP determines absorptive or secretory responses in the rat jejunum. J Clin Invest 103:167-174

27. Massey-Harroche D 2000 Epithelial cell polarity as reflected in enterocytes. Microsc Res Tech 49:353-362

28. Boucher MJ, Rivard N 2003 Regulation and role of brush border-associated ERK1/2 in intestinal epithelial cells. Biochem Biophys Res Commun 311:121-128

29. Boucher MJ, Jean D, Vézina A, Rivard N 2004 Dual role of MEK/ERK signaling in senescence and transformation of intestinal epithelial cells. Am J Physiol Gastrointest Liver Physiol 286:G736-G746

30. Halbleib JM, Sääf AM, Brown PO, Nelson WJ 2007 Transcriptional modulation of genes encoding structural characteristics of differentiating enterocytes during development of a polarized epithelium in vitro. Mol Biol Cell 18:4261-4278 
31. Ghanekar Y, Chandrashaker A, Visweswariah SS 2003 Cellular refractoriness to the heat-stable enterotoxin peptide is associated with alterations in levels of the differentially glycosylated forms of guanylyl cyclase C. Eur J Biochem 270:3848-3857

32. Qian X, Prabhakar S, Nandi A, Visweswariah SS, Goy MF 2000 Expression of GC-C, a receptor-guanylate cyclase, and its endogenous ligands uroguanylin and guanylin along the rostrocaudal axis of the intestine. Endocrinology 141:3210-3224

33. Anand RJ, Leaphart CL, Mollen KP, Hackam DJ 2007 The role of the intestinal barrier in the pathogenesis of necrotizing enterocolitis. Shock 27:124-133
34. Li P, Schulz S, Bombonati A, Palazzo JP, Hyslop TM, Xu Y, Baran AA, Siracusa LD, Pitari GM, Waldman SA 2007 Guanylyl cyclase C suppresses intestinal tumorigenesis by restricting proliferation and maintaining genomic integrity. Gastroenterology 133:599-607

35. Bryant AP, Busby RW, Bartolini WP, Cordero EA, Hannig G, Kessler MM, Pierce CM, Solinga RM, Tobin JV, Mahajan-Miklos S, Cohen MB, Kurtz CB, Currie MG 2010 Linaclotide is a potent and selective guanylate cyclase C agonist that elicits pharmacological effects locally in the gastrointestinal tract. Life Sci 86:760-765 